\title{
The Simulation Olympics: a resuscitation-based simulation competition as an educational intervention
}

\author{
J. Damon Dagnone, MD, MSc, MMEd*; Amandeep Takhar, BSc, MD*; Lauren Lacroix, BSc $^{\dagger}$
}

\begin{abstract}
The Department of Emergency Medicine at Queen's University developed, implemented, and evaluated an interprofessional simulation-based competition called the Simulation Olympics with the purpose of encouraging health care providers to practice resuscitation skills and foster strong team-based attitudes. Eleven teams $(N=45)$ participated in the competition. Teams completed three standardized resuscitation scenarios in a high-fidelity simulation laboratory with teams composed of nurses, respiratory therapists, and undergraduate and postgraduate medical trainees. Trained standardized actors and a dedicated technician were used for all scenarios. Judges evaluated team performance using standardized assessment tools. All participants $(100 \%)$ completed an anonymous two-page questionnaire prior to the competition assessing baseline characteristics and evaluating participant attitudes, motivation, and barriers to participation. The majority of participants $(71 \%)$ completed an evaluation form following the event focusing on highlights, barriers to participation, and desired future directions. Evaluations were uniformly positive in short-answer feedback and attitudinal scoring measures. To our knowledge, the Simulation Olympics competition is the first of its kind in Canada to be offered at an academic teaching hospital.
\end{abstract}

\section{RÉSUMÉ}

Le département de médecine d'urgence de I'Université Queen's a élaboré, réalisé, et évalué une compétition interprofessionnelle, axée sur la simulation et appelée "Simulation Olympics ", dans le but d'inciter des professionnels de la santé à mettre en pratique leurs compétences en réanimation et de faciliter l'adoption de fortes attitudes d'équipe. Onze équipes $(N=45)$ ont participé à la compétition. Les équipes, composées d'infirmières, d'inhalothérapeutes, d'étudiants diplômés, et non diplômés en médecine, ont concouru dans trois scénarios uniformes de réanimation, dans un laboratoire simulant très bien la réalité. Des acteurs normalisés, ayant reçu une formation particulière, et un technicien dévoué étaient présents dans tous les scénarios. Les juges ont évalué la performance des équipes à l'aide d'outils d'évaluation normalisés. Tous les participants (100\%) ont répondu à un questionnaire anonyme, de deux pages, avant la compétition, visant à évaluer leurs caractéristiques de base, leurs attitudes, et leur motivation ainsi que les obstacles à la participation. La plupart des participants $(71 \%)$ ont rempli un formulaire d'évaluation après la compétition, portant surtout sur les faits saillants, les obstacles à la participation, et les orientations futures souhaitées. Les évaluations se sont révélées uniformément favorables dans de courtes rétroactions et des mesures de cotation des attitudes. À notre connaissance, la compétition "Simulation Olympics " est la première du genre, au Canada, à avoir été organisée dans un hôpital d'enseignement.

Keywords: interprofessional, resuscitation, simulation

Team-based simulation training is increasingly used to train interprofessional teams. ${ }^{1}$ The benefits of using simulation-based team training have been well described previously ${ }^{2}$ and centre around an adult learning approach, which offers its learners deliberate practice and context-dependent and experiential learning.

Numerous studies have demonstrated the benefits of integrating simulation-based training with an interprofessional approach..$^{3-6}$ Physicians trained with simulation provide a higher level of care in resuscitation/ cardiac arrest, ${ }^{3,4}$ improve the efficiency of team performance,, 5 and reduce the rate of medical error, thus minimizing patient harm. ${ }^{\circ}$

Unfortunately, innovations in medical education delivery are often slow to be implemented and may be

From the *Department of Emergency Medicine, Faculty of Health Sciences, and TSchool of Medicine, Queen's University, Kingston, ON.

Correspondence to: Dr. J. Damon Dagnone, Department of Emergency Medicine, Faculty of Health Sciences, Queen's University, 76 Stuart Street, Empire 3, KGH, Kingston, ON K7L 2V7; damondagnone@hotmail.com.

This article has been peer reviewed.

(c) Canadian Association of Emergency Physicians 
due to many practical issues, including scheduling conflicts, staff training, conflicting financial priorities, lack of laboratory space, and expertise. ${ }^{7}$ To successfully introduce innovation, a project often requires partnerships between experienced staff and faculty champions.

\section{RATIONALE}

In an effort to stimulate interprofessional team training in resuscitation at our academic teaching hospital, an annual simulation-based resuscitation competition named the "Simulation Olympics" was launched as a pilot project following the 2010 Winter Olympics. The Simulation Olympics is a 3-day simulation-based competition with associated preparatory training sessions where interprofessional teams composed of individuals from across our hospital compete against each other in standardized resuscitation scenarios. The format was adapted from Okuda and colleagues' "Sim Wars" competition, first introduced at the American College of Emergency Physicians conference in Chicago in 2008..$^{9,10}$

With the support of senior administration at the hospital and university, the competition has served to promote the development and implementation of additional simulation-based team training initiatives at our institution.

\section{DESCRIPTION OF INNOVATION}

\section{Competition design}

The Simulation Olympics was designed as a 3-day interprofessional competition, with 2 days of preliminary rounds and 1 day of final round competition. Sequestered interprofessional teams competed in the same three scenarios on the first 2 days and were scored by a panel of faculty experts using standardized assessment tools developed specifically for the competition (see the Appendix for scenario 1). The top three scoring teams advanced to the final round, where the teams participated in a resuscitative scenario in a university auditorium before their peers and fellow competitors. The finals were judged by a panel of four expert faculty members. Funding for faculty judges, awards, and laboratory time was provided through a combination of a university postgraduate education grant, support from the departments of Emergency
Medicine and Internal Medicine, and the Kingston Resuscitation Institute.

\section{Participants}

Participants for the competition were recruited from across the hospital from numerous specialties, including emergency medicine, internal medicine, critical care, family medicine, and anesthesia. Previous participant training in a simulation environment was quite variable. Numerous hospital staff (specifically registered nurses, respiratory therapists, and paramedics) had no previous high-fidelity simulation-based training encounters and, similarly, no formal interprofessional team training experiences. Undergraduate and postgraduate medical trainees also had quite variable experiences. Previous simulation training for the medical trainees varied from 5 to 10 hours of previous experience (senior medical students, internal medicine and family medicine residents) to 20 to 50 hours (critical care and anesthesia residents), to more than 100 hours per year (emergency medicine residents). This is explained by the formal simulation-based simulation curricula each program employs at Queen's University.

Teams were composed of four or five members and were required to have at least one nonphysician member, which could include a registered nurse, respiratory therapist, paramedic, or medical student. Faculty coaches assisted with team preparation, performance, and debriefing during the competition. Preliminary training sessions for team orientation and practice were held for all teams in the month prior to the competition. Content was focused on crisis resource management skills, Advanced Cardiac Life Support (ACLS) algorithms, and principles of resuscitationbased care. These sessions were coordinated by at least one faculty instructor and an experienced simulation technician.

\section{Expert panel and scoring tools}

Judges were chosen from clinician experts from medicine and nursing (departments of Emergency Medicine, Internal Medicine, and Critical Care) and trained to use the standardized scoring tool for each competition scenario. The scoring tool design was based on previous and ongoing validated simulation-based assessment tools for resuscitation at Queen's University. ${ }^{11}$ 


\section{Scenarios}

The scenarios were designed by emergency medicine faculty with training in high-fidelity simulation-based instruction. Each preliminary round scenario took place in the Kingston Resuscitation Institute's simulation laboratory, a single resuscitation room setup with an attached control room and a debriefing room across the hall. The preliminary round scenarios were 1) pulseless electrical activity caused by anaphylaxis, 2) prolonged QT in a sedated patient in restraints, and 3) alcohol withdrawal seizure complicated by a disruptive family member. All scenarios were designed to challenge the management of cardiac arrest and cardinal symptom management, as well as crisis resource management skills in a resuscitation situation. Each station lasted 6 minutes and included various scripted roles involving a nurse, the patient's family member, or a (respiratory therapist) technician. Judges used scoring flow sheets to evaluate team performance based on clinical decision making, team communication, leadership, and global assessment (see the Appendix). The final competition scenario was third-degree atrioventricular block (long QTi) in a young woman with bulimia conducted outside the simulation laboratory (university auditorium), where teams only had access to a crash cart.

\section{Funding and administration}

With the support of senior administration, the resources required to facilitate the competition were identified and funded. An initial budget of $\$ 20,000$ was allocated for the 2011 event. This included funding for simulation laboratory time and space, faculty champions, technician time, recruitment of trainees and hospital staff, simulation technician time, standardized actors to help carry out the scenarios, and competition prizes.

\section{Questionnaire/evaluations}

Participants were asked on the first day to fill out an anonymous questionnaire. The first section was composed of eight items addressing participants' level of training and past experiences in simulation, interprofessional, and resuscitation training (Table 1). The questions also evaluated team preparation for the competition and barriers to team practice prior to the competition. The second section was designed to evaluate participant attitudes and motivation toward

\begin{tabular}{|c|c|}
\hline Statement & Total $(\%)$ \\
\hline \multicolumn{2}{|l|}{ Training level } \\
\hline Registered nurse & $8(19)$ \\
\hline Paramedic & $1(2)$ \\
\hline Respiratory therapist & $1(2)$ \\
\hline Medical student & $14(31)$ \\
\hline FRCP-EM resident & $12(26)$ \\
\hline CCFP-EM resident & 2 (5) \\
\hline Internal medicine resident & $5(11)$ \\
\hline Anesthesia resident & $1(2)$ \\
\hline Critical care resident & $1(2)$ \\
\hline Total & $45(100)$ \\
\hline \multicolumn{2}{|c|}{$\begin{array}{l}\text { Total hours of simulation training } \\
\text { received in the last } 12 \mathrm{mo}\end{array}$} \\
\hline 0 & $6(15)$ \\
\hline $1-4$ & $4(9)$ \\
\hline $5-10$ & $6(15)$ \\
\hline $11-20$ & 13 (29) \\
\hline $21-50$ & $8(20)$ \\
\hline$>50$ & $8(20)$ \\
\hline \multicolumn{2}{|c|}{$\begin{array}{l}\text { Total hours of interprofessional team } \\
\text { training ( }>1 \text { specialty) in the last } 12 \mathrm{mo}\end{array}$} \\
\hline 0 & $15(33)$ \\
\hline $1-4$ & $15(33)$ \\
\hline $5-10$ & $7(16)$ \\
\hline $11-20$ & $4(9)$ \\
\hline $21-50$ & $4(9)$ \\
\hline$>50$ & $0(0)$ \\
\hline \multicolumn{2}{|c|}{$\begin{array}{l}\text { Total number of cardiac arrest or critical } \\
\text { event patient encounters in the last } 12 \mathrm{mo}\end{array}$} \\
\hline 0 & $13(29)$ \\
\hline $1-3$ & $7(15)$ \\
\hline $4-10$ & $13(29)$ \\
\hline $11-20$ & $5(11)$ \\
\hline $21-50$ & $4(9)$ \\
\hline$>50$ & $2(5)$ \\
\hline
\end{tabular}

resuscitation and simulation training. Participants were also asked to complete an evaluation of the competition following the event. The evaluation form asked for participants to provide comments on the highlights of the event and offer suggestions for improvement. This study was approved by the Queen's University Health Sciences and Affiliated Teaching Hospitals Research Ethics Board.

\section{RESULTS}

Eleven teams composed of 4 (or 5 ) team members $(N$ $=45$ ) participated in the Simulation Olympics. The competition had nine staff physician faculty coaches, 
seven faculty judges, a simulation laboratory technician, three actors, and a faculty coordinator. Seven teams took advantage of the supervised 2-hour practice sessions made available prior to the competition, with one team practicing twice. Two teams, composed of medical students, prepared specifically for the competition (10-12 hours) with a faculty coach in the months leading up to the competition.

Fundraising for the 2011 event succeeded in collecting \$16,000 from the following groups: Queen's School of Medicine $(\$ 10,000)$, Kingston Resuscitation Institute $(\$ 3,000)$, Department of Emergency Medicine $(\$ 2,000)$, and the Department of Internal Medicine $(\$ 1,000)$. The Simulation Olympics director was appointed to the hospital's Inter-professional Education Steering Committee to promote simulation-based team training initiatives and develop long-term funding opportunities with the hospital's board of governors and private donors.

Questionnaires were completed by all 45 participants prior to the competition. Participant characteristics, including their training levels, are outlined in Table 1. Medical residents (47\%) and medical students (31\%) formed the majority of 2011 competition participants. Other participants included registered nurses $(18 \%)$, a respiratory therapist $(2 \%)$, and one paramedic $(2 \%)$.

In the 12 months prior to the competition, the three most successful teams advancing to the finals had at least two of four members receive 21 to 50 hours of interprofessional simulation-based team training. This is in contrast to the two-thirds of participants receiving an average of less than 5 hours of interprofessional team training over the last 12 months prior to the competition. Approximately $76 \%$ of participants were involved in the care of a cardiac arrest or race team patient in the last year, with a great proportion caring for an average of 4 to 10 patients. The top two reasons identified as barriers to team practice time were the following: 1) interprofessional team schedules were too difficult to coordinate and 2) clinical responsibilities did not permit practice.

All participants reported confidence in delivering chest compressions, and nearly all participants (95.6\%) were comfortable with requesting help in patient management during a resuscitation event. Almost three-quarters of participants reported feeling comfortable with managing a patient's airway and obtaining intravenous access to deliver medications during a resuscitation effort. A majority of participants (84.4\%) were comfortable with obtaining a cardiac rhythm and using the Lifepac monitor/defibrillator to cardiovert, defibrillate, or pace a patient during a resuscitation event. Sixty percent of participants reported feeling comfortable acting as a team leader in a resuscitation effort. Furthermore, an overwhelming majority of participants expressed an interest in participating in additional resuscitation training within a simulationbased and interprofessional setting.

Evaluations were completed by 32 participants. All participants but one "strongly agreed" or "agreed" to statements expressing satisfaction with the event and the desire for further events and programming in resuscitative care using a simulation-based, interprofessional setting.

\section{DISCUSSION}

The Simulation Olympics was implemented to promote simulation-based competition assessing teambased resuscitation skills. By many measurements, the competition was a success. This is evident in the positive feedback from participants and faculty involved; the funds generated to carry out the event; the involvement of numerous trainees, hospital staff, and medical and nursing faculty; and the support of senior administrators at both the hospital and university levels. Perhaps most importantly, the event has served as a catalyst to bring together medical educators to develop, implement, and evaluate additional simulationbased team training initiatives at our institution.

The results from both the questionnaire and evaluation forms suggest that the Simulation Olympics was a meaningful educational initiative. Most notably, all participants expressed a strong desire for the continued expansion of this competition and a desire to expand the formal simulation-based interprofessional resuscitation training program as a whole within departments. Verbal feedback (not recorded in the questionnaire) by numerous nurse participants included requests for the hospital's administration to provide specifically identified simulation-based team training in resuscitation.

The implementation of this team-based competition came with numerous lessons learned. The organizational framework required to execute this event was overwhelming to the competition director, and further administrative support is required for future competitions. Funding and administrative support, although 
positive, also presented many challenges. With hospital and university budgets becoming less flexible with each passing year, the ability of this competition to expand will depend on senior administrators providing financial support, space, and the ability of hospital staff and medical faculty to train and teach, without clinical or financial consequence. Starting in 2012, our academic teaching hospital has committed matching funds to the university's contribution. The creation of an interprofessional steering committee to help direct and expand the development of hospital-based team training initiatives using simulation and other methods was also encouraging, along with the Simulation Olympics event director being named co-chair.

More participants from other professions are needed to maximize the interprofessional component of this event. Many hospital staff, specifically registered nurses and respiratory therapists, are hesitant to participate in the competition and practice sessions due to the uncertainty and fear associated with being evaluated in an interprofessional simulation setting. Additional simulation-based team training initiatives have been introduced and must continue to overcome these challenges. At the time of publication, the 2012 Simulation Olympics was held with over 90 participants (approximately 50\% were hospital staff) from 19 teams across 5 specialty programs. Three teams from Montreal and Toronto participated in the event.

To our knowledge, this competition is the first of its kind in Canada to be offered at an academic teaching hospital and was adapted from similar competitions held by Okuda and colleagues., ${ }^{90}$ They have had similar success in offering team-based competitions in resuscitation for the last 3 years in the United States, at both their academic centre and international conferences for the Society for Academic Emergency Medicine and the Society for Simulation in Healthcare. Future directions at our institution are focused on expanding the competition within our centre and the region, developing and implementing novel interprofessional resuscitation training educational initiatives, and working toward an evidence-based framework that demonstrates a clinical impact from these initiatives.

\section{SUMMARY}

The Simulation Olympics was a successful, wellexecuted, and well-funded educational project. The participants in this hospital-wide simulation-based interprofessional competition were extremely satisfied with the event and expressed a strong desire to expand interdisciplinary team training in resuscitation in our hospital. With this study, significant barriers to interprofessional team training at our institution have been identified, and plans for the continued growth of this project are under way.

Competing interests: None declared.

\section{REFERENCES}

1. Villamaria FJ, Pliego JF, Wehbe-Janek H, et al. Using simulation to orient code blue teams to a new hospital facility. Simul Healthc 2008;3:209-16, doi:10.1097/SIH. 0b013e31818187f3.

2. Walter E, Howard V, Vozenilek J, et al. Simulation-based team training in healthcare. Simul Healthc 2011;6 Suppl 7:S14-9, doi:10.1097/SIH.0b013e318229f550.

3. Capella J, Smith S, Philp A, et al. Teamwork training improves the clinical care of trauma patients. 7 Surg Educ 2010;67:439-43, doi:10.1016/j.jsurg.2010.06.006.

4. Hunt EA, Shilkofski NA, Stavroudis TA, et al. Simulation: translation to improved team performance. Anesthesiol Clin 2007;25:301-19, doi:10.1016/j.anclin.2007.03.004.

5. Lighthall GK, Poon T, Harrison TK. Using in situ simulation to improve in-hospital cardiopulmonary resuscitation. Ft Comm 7 Qual Patient Saf 2010;36:209-16.

6. Long RE. Using simulation to teach resuscitation: an important patient safety tool. Crit Care Nurs Clin North Am 2005;17:1-8, doi:10.1016/j.ccell.2004.09.001.

7. Siegfried JJ, Getz M, Anderson KH. The snail's pace of innovation in higher education. Chron Higher Educ 1995; May 19:A56.

8. Dagnone D, Takhar A, Howes D. The development and implementation of a novel simulation-based interprofessional resuscitation competition. The Simulation Olympics. Presented at the International Conference on Residency Education: Simulation Summit; 2011 Nov; Montreal, PQ.

9. Okuda Y, Godwin A, Westenbarger R, et al. "Sim Wars": a new edge to academic residency competitions. Acad Emerg Med 2009;16 Suppl 1:S275-6, doi:10.1111/j.1553-2712. 2009.00392_4.x.

10. Okuda Y, Godwin A, Westenbarger R, et al, "Sim Wars" competition at International Meeting on Simulation in Health Care Annual Conference, Fanuary 2011. Available at: http:// www.ssih.org/imsh20101/imsh20101/imsh2011simwars1/ (accessed December 1, 2011).

11. Hall AK, Pickett W, Dagnone JD. Development and evaluation of a simulation-based resuscitation scenario assessment tool for emergency medicine residents. CFEM 2012;14:139-46. 


\section{APPENDIX: SAMPLE JUDGES' SCORING SHEET FOR PRELIMINARY SCENARIO 1}

\section{Scenario 1: PEA secondary to anaphylaxis (IV contrast reaction)}

Team Identification:

Judge Identification:

\begin{tabular}{|c|c|c|c|c|}
\hline \multicolumn{5}{|l|}{ Primary Assessment } \\
\hline \multicolumn{2}{|l|}{ VITAL signs ABSENT } & \multicolumn{2}{|c|}{ Airway assessment } & \\
\hline \multicolumn{2}{|l|}{ PACER PADS placed } & \multirow{2}{*}{\multicolumn{2}{|c|}{ Rhythm assessment }} & \\
\hline \multicolumn{3}{|l|}{ IV access } & & \\
\hline 1 & 2 & 3 & 4 & 5 \\
\hline INFERIOR & NOVICE & COMPETENT & ADVANCED & SUPERIOR \\
\hline $\begin{array}{l}\text { Delayed or incomplete } \\
\text { performance of } \\
\text { all criteria }\end{array}$ & $\begin{array}{l}\text { Delayed or incomplete } \\
\text { performance of } \\
\text { many criteria }\end{array}$ & $\begin{array}{l}\text { Delayed or incomplete } \\
\text { performance of } \\
\text { some criteria }\end{array}$ & $\begin{array}{l}\text { Competent } \\
\text { performance } \\
\text { of most criteria }\end{array}$ & $\begin{array}{l}\text { Efficient and rapid } \\
\text { performance of } \\
\text { all criteria }\end{array}$ \\
\hline \multicolumn{5}{|l|}{ Diagnostic Workup } \\
\hline \multicolumn{2}{|l|}{$\begin{array}{l}\text { History (SOB/pain, } \\
\text { PMHX, Meds, Allergies) }\end{array}$} & \multicolumn{2}{|c|}{ MEDICAL RECORD explored } & \\
\hline \multicolumn{2}{|l|}{ Physical Exam } & \multicolumn{2}{|c|}{ ECG \& CXR post-ROSC } & \\
\hline 1 & 2 & 3 & 4 & 5 \\
\hline INFERIOR & NOVICE & COMPETENT & ADVANCED & SUPERIOR \\
\hline $\begin{array}{l}\text { Delayed or incomplete } \\
\text { performance of all criteria }\end{array}$ & $\begin{array}{l}\text { Delayed or incomplete } \\
\text { performance of } \\
\text { many criteria }\end{array}$ & $\begin{array}{l}\text { Delayed or incomplete } \\
\text { performance of } \\
\text { some criteria }\end{array}$ & $\begin{array}{l}\text { Competent } \\
\text { performance of } \\
\text { most criteria }\end{array}$ & $\begin{array}{l}\text { Efficient and rapid } \\
\text { performance of } \\
\text { all criteria }\end{array}$ \\
\hline \multicolumn{5}{|l|}{ Therapeutic Actions } \\
\hline \multicolumn{2}{|l|}{$\begin{array}{l}\text { Positive Pressure } \\
\text { Ventilation }\end{array}$} & \multicolumn{2}{|c|}{ DRUGS: IV EPI/H-blockers/steroid /IVF } & \\
\hline \multirow{2}{*}{\multicolumn{2}{|c|}{ Supplemental $\mathrm{O}_{2}$}} & \multirow{2}{*}{\multicolumn{2}{|c|}{$\begin{array}{l}\text { Consideration of intubation } \\
\text { Considers COOLING post-ROSC }\end{array}$}} & \\
\hline & & & & \\
\hline 1 & 2 & 3 & 4 & 5 \\
\hline INFERIOR & NOVICE & COMPETENT & ADVANCED & SUPERIOR \\
\hline $\begin{array}{l}\text { Delayed or incomplete } \\
\text { performance of } \\
\text { all criteria }\end{array}$ & $\begin{array}{l}\text { Delayed or incomplete } \\
\text { performance of many } \\
\text { criteria }\end{array}$ & $\begin{array}{l}\text { Delayed or incomplete } \\
\text { performance } \\
\text { of some criteria }\end{array}$ & $\begin{array}{l}\text { Competent } \\
\text { performance of } \\
\text { most criteria }\end{array}$ & $\begin{array}{l}\text { Efficient and rapid } \\
\text { performance of } \\
\text { all criteria }\end{array}$ \\
\hline \multicolumn{5}{|l|}{ Communication } \\
\hline \multicolumn{2}{|c|}{ Introduces self and explains clinical situation } & \multicolumn{3}{|c|}{ Demonstrates leadership in managing crisis } \\
\hline \multicolumn{2}{|c|}{ Clear and concise orders and direction } & \multicolumn{3}{|c|}{ Manages distracting individuals } \\
\hline \multicolumn{2}{|c|}{ Prioritizes tasks and anticipates further steps } & \multicolumn{2}{|c|}{ Request for family members } & \\
\hline 1 & 2 & 3 & 4 & 5 \\
\hline INFERIOR & NOVICE & COMPETENT & ADVANCED & SUPERIOR \\
\hline $\begin{array}{l}\text { Delayed or incomplete } \\
\text { performance of all criteria }\end{array}$ & $\begin{array}{l}\text { Delayed or incomplete } \\
\text { performance of } \\
\text { many criteria }\end{array}$ & $\begin{array}{l}\text { Delayed or incomplete } \\
\text { performance of } \\
\text { some criteria }\end{array}$ & $\begin{array}{l}\text { Competent } \\
\text { performance of } \\
\text { most criteria }\end{array}$ & $\begin{array}{l}\text { Efficient and rapid } \\
\text { performance of } \\
\text { all criteria }\end{array}$ \\
\hline \multicolumn{5}{|l|}{ OVERALL PERFORMANCE } \\
\hline 1 & 2 & 3 & 4 & 5 \\
\hline INFERIOR & NOVICE & COMPETENT & ADVANCED & SUPERIOR \\
\hline $\begin{array}{l}\text { All skills require significant } \\
\text { improvement } \\
\text { Additional Comments }\end{array}$ & $\begin{array}{l}\text { Most skills require } \\
\text { moderate or significant } \\
\text { improvement }\end{array}$ & $\begin{array}{l}\text { Some skills require } \\
\text { moderate } \\
\text { improvement }\end{array}$ & $\begin{array}{l}\text { Some skills require } \\
\text { minor improvement }\end{array}$ & $\begin{array}{l}\text { Few, if any, skills } \\
\text { require only minor } \\
\text { improvement }\end{array}$ \\
\hline
\end{tabular}

